\title{
Education Intervention Guideline on Knowledge and Self-Care Practice for Women With Vulvovaginities
}

\author{
Samah Abd Elhaleim Said ${ }^{1}$, Hemmat Mostafe Elbana ${ }^{1} \&$ Amira mohammed salama ${ }^{1}$ \\ ${ }^{1}$ Maternal and Newborn Health Nursing, Benha University, Egypt \\ Correspondence: Samah Abd Elhaleim Said, Assistant professor, Maternal and Newborn Health Nursing, Benha \\ University, Egypt.
}

Received: January 21, 2019

Accepted: February 28, 2019

Online Published: March 8, 2019

doi:10.20849/ijsn.v4i1.552

URL: https://doi.org/10.20849/ijsn.v4i1.552

\begin{abstract}
Background Bacterial vaginosis (BV) is the most common vaginal infection affecting women of reproductive age (15-49 years of age). 5-8\% of women with acute infection experience recurrent vulvo-vaginal candidiasis. Side effects of vaginitis can affect other aspects of health, which could be prevented by promoting a healthy related to vaginal health. Aim of the study. The aim of the present study was to evaluate the Education intervention guideline on knowledge and self-care practice for women with vulvovaginities. Design: A quasiexperimental design was adopted in the current study. Sample: A purposive sample of (130) women's were included in the current study. Setting: the current study was conducted at outpatient clinic affiliated at obstetric department at Benha University Hospital. Data collection: Two tools were used for data collection, first, interviewing questionnaire to collect data about the women' socio demographic characteristics and women's knowledge regarding vulvovaginities as definition, risk factors, complication, second tool, Self-Care Assessment Structured Interviewing Schedule as (Clean genital area after each toilet, dry after cleanliness) Results: the result of the present study should that the total knowledge was improved from $(9.2 \%)$ at pre intervention to $(86.2 \%)$ at post intervention phase. In addition there was demonstrates that, $87.7 \%$ of the women had an unsatisfactory level of self-care practices before the educational intervention. Meanwhile, after the educational intervention, 75.4\% of them got a satisfactory level of self-care practices. Conclusion: Educational intervention was effective in improving the women's knowledge and self-care practices regarding vulvovaginities. Recommendations: Provide different educational programs regarding knowledge and self-care practice for women with vulvovaginities at different female health care settings.
\end{abstract}

Keywords: guideline, valvovaginities, knowledge, self-care practice, women

\section{Introduction}

Reproductive tract infections (RTIs), generally seen as a silent epidemic, is one of the major public health problems causing a considerable proportion of gynecological morbidity and maternal mortality in the developing countries Ali and hussien (2017). Vulvovaginitis is considered the most common type of reproductive system infections and refers to any inflammation or infection of the vagina and external genitalia. This is a common gynecological problem found in women of all ages, with most having at least one form of vaginitis at some time during their life. Vaginitis can occur when the walls of the vagina become inflamed or some irritant has disturbed the balance of the vagina Gor (2015).

It was reported that the incidence of symptomatic women with bacterial vaginosis (40-45\%), vaginal candidiasis (20-25\%), and trichomoniasis (15-20\%); yet $7-72 \%$ of women with vaginitis may remain undiagnosed. World health organization (2013). Vaginitis affects women of all ages but is most common during the reproductive years .It occurs in $1 \%-14 \%$ of all women of reproductive age. The highest incidence is noted among young, sexually active women. About $40 \%$ to $50 \%$ of women who experience a first episode are likely to experience recurrence and 5\% may present a form of "recurring" vaginitis characterized by at least three or more episodes of infection per year Barry and Maria (2011).

The symptoms of BV include an abnormal odour and increased discharge Yarmohammadi (2015). Past studies have found the symptoms of BV to be highly distressing and embarrassing to women, impacting significantly on their self-esteem and sexual relationships and making them feel 'dirty', embarrassed, ashamed, self-conscious and fearful others will detect their abnormal odour and discharge Bilardi et al (2016). 
Vulvovaginitis is a global health problem which affects women. These infections threat the women's health and may have severe consequences such as infertility, ectopic pregnancy, chronic pelvic pain, abortion and an increased risk of HIV transmission. Therefore, proper prevention and treatment of these diseases are of great importance Mulu et al. (2015).

Nowadays, considering the importance of the self-care in health promotion, lifestyle modification, disease prevention, symptoms evaluation, health protection, treatment and rehabilitation as a complement for health specialized care, the methods for establishment of self-care behaviours are emphasized in disease management Ebrahim et al. (2015) Since knowledge and awareness play crucial role in individuals' attitude, behaviour and practice, and since favourable practice is possible through acquiring knowledge and changes in attitude, education is of outmost importance that will result in disease recuperation and complications control Gupta et al. (2013).

Nurses play a critical part in identifying vaginal discharges-an important finding that may assist in preventing situations which lead to gynaecologic infections-as well as in ensuring that the patients comply with the recommended analyses and treatments and in finding out wrong hygiene habits and determining the correct practices and can undertake the role of a health educator and mentor through proper approaches in identifying and resolving gynaecologic problems Eman elsayed (2016).

\subsection{Significance of the Study}

Generally, reproductive tract infections are 'silent' .Major women public health problems causing discomfort, anxiety affecting women's quality of life. While vaginal infection is one of the most common gynecological infections World health organization (2013). Few studies have explored in-detail women's knowledge and self-care practice regarding bacterial vaginosis. Untreated infections can not only lead to health consequences but females may experience social consequences in terms of emotional distress related to gynecological morbidity. Past research has shown women often feel dissatisfied with the clinical care they receive when presenting with vaginal symptoms and both women and clinicians frequently misdiagnose BV. So the present study was conducted to evaluate the effect of educational intervention guideline on knowledge and self-care practices for women with vulvovaginitis.

\subsection{Aim of the Study}

The aim of the present study was to evaluate the effect of educational intervention guideline on knowledge and self-care practices for women with vulvovaginitis.

\subsection{Research Hypothesis}

Educational intervention guideline exhibit improvement in knowledge and self-care practices among women with vulvovaginities.

\section{Subjects and Method}

\subsection{Research Design}

A quasi-experimental design was used in the present study.

2.2 Setting

The study was conducted at gynecological department and outpatient clinic affiliated to Benha University Hospital.

\subsection{Subject Type and Criteria}

A purposive sample of 130 reproductive-aged women with vulvovaginities were recruited for the study according to the following inclusion criteria; women diagnosed with vulvovaginities, in childbearing period, free from medical disease and accepted to participate in the study.

\subsection{Subject Size}

Subject size was calculated based on the previous six months census report of Benha University hospital. The total number of women with vulvovaginities $=(196)$ women Sample size was calculated using the present formula.

$$
\mathrm{n}=\frac{\mathrm{N}}{1+\mathrm{N}(\mathrm{e}) 2}
$$


Where:

$$
\begin{gathered}
\mathrm{N}=\text { total population number }(196) . \\
\mathrm{n}=\text { sample size }=130 \\
\mathrm{e}=\text { margin error }(0.05)
\end{gathered}
$$

\subsection{Tools of Data Collection}

Tools of data collection: Two main tools were used for data collection:

\subsubsection{Structured Interviewing Questionnaire}

It was designed by the researchers after reviewing related literature. It was written in an Arabic language in the form of closed and open-ended questions. It encompassed two major parts:

Part I: included demographic data such as (age, educational level, residence, occupation. etc ....).

Part II: included women' knowledge about vulvovaginitis infection as (definition, causative agents of vulvovaginitis, causes, symptoms, complications, preventive measures of vulvovaginitis). This part was used before and after implementation of the educational intervention program (pre/ post-test format)

\section{Scoring system of knowledge}

Each questions had a number of correct answer each studied sample was asked to select more than answer for each answer was given 1 for correct and 0 for not correct. The mean and standard deviation was calculated. In addition, the score of total knowledge was divided into two levels, the woman was considered to have adequate Knowledge if the score was $\geq 60 \%$, and inadequate if $<60 \%$.

\subsubsection{Self-Care Assessment Structured Interviewing Schedule}

It was developed by the researcher to collect data related to women' reported self-care practices including their personal daily habits as measures taken by women's to prevent vulvovaginitis infection as (Clean genital area after each toilet, dry after cleanliness, wear cotton underwear, wear loose under wear, etc...)

\section{1). Scoring system of practices}

The score for self-care practice was ranged from 1 to 0 as follow, each statement took (1) score if done, (and (0) if not done. The total score of practices was divided into two levels, where the woman who was their practices scores $\geq 60 \%$, they considered on the satisfactory level, and those who were score $<60 \%$ are on unsatisfactory level.

\section{2). Supported materials developed intervention guidelines}

These guidelines were prepared by the researcher based on review of pertinent literature. It was meant to be used to help women know, understand and perform healthy self-care practices in their daily life to relieve vulvovaginitis infection symptoms and to prevent its recurrence. The intervention guidelines covered theoretical and practical sections such definition, causes, risk factors, clinical manifestations, and adverse effect of vulvovaginitis. In addition, management and preventive measures, also hygienic care of the genital tract (the healthy behavior or healthy self care practices).

\subsection{Tools Validity and Reliability}

Tools were reviewed by a panel of five experts in the field of obstetrics and woman health nursing to test its content validity. Modifications were done accordingly based on their judgment. Reliability was done by Cronbach's Alpha coefficient test (Test-retest was repeated to the same sample of studied women on two occasions) the scores revealed that each of the two tools consisted of relatively homogenous items as indicated by the moderate to high reliability (internal consistency) of each tool (knowledge $=0.879$ and self-care practices $=0.869$ ).

\subsection{Administrative and Ethical Considerations}

Official written approvals were obtained from Benha University Hospital administrators and head of the concerned department. Each woman was informed about the purpose of the study, confidentiality was ensured throughout the study process, and the women were assured that all data was used only for research purpose. Each woman was informed that participation is voluntary and free to withdraw from the study at any time.

\subsection{Pilot Study}

A pilot study was carried out before starting the data collection and conducted on $10 \%$ of the total sample (6 women) to test the feasibility of the study and applicability of the tools and to determine the possible obstacles 
and problems that might face the researcher and affect data collection and to find any problems peculiar to the statements as sequence of questions and clarity. It also assists to estimate the time required for data collection. After conducting the pilot study, it was found that the sentences of the tools were clear and relevant, but few words have been modified according to pilot study results. The women included in the pilot study were excluded from the main study sample.

\subsection{Field Work}

The study was carried out through four phases: assessment, planning, implementation, and evaluation. These phases were carried out from beginning of February, 2017 to the end of July 2017, covering along a period of six months. The previous mentioned setting was visited by the researchers three days/week (Saturday, Tuesday, and Thursday) from $9.00 \mathrm{Am}$ to $12.00 \mathrm{pm}$.

\subsubsection{Assessment Phase}

Upon securing official permissions to conduct the present study, each woman was interviewed individually; aim of the study and procedure of the study was explained, and asked for her participation. women' knowledge and self-care reported practice were assessed utilizing the tools of data collection. Based on the result of pre-test the studied women needs regarding knowledge and self-care reported practice was detected. The data obtained during this phase constituted the baseline for further comparisons to evaluate the effect of the educational intervention.

\subsubsection{Planning Phase}

Based on the results obtained from the interview sheet from pilot study and assessment phase (pre-test) as well as reviewing the related literature the educational intervention guideline were developed by the researchers. Detected needs, requirements and deficiencies were translated into the aim and objectives of the educational intervention. The contents of the educational intervention guidelines were selected on the basis of identified needs. Different teaching strategies and teaching methods were selected to suit teaching in small groups in a form of group discussion. The general objective the program was to evaluate the effect of educational intervention guideline on knowledge and self-care practice for women with vulvovaginities. The content of the program was designed to meet women's needs regarding knowledge and self-care reported practice regarding vulvovaginities.

Specific objectives: by completion of the educational intervention, each woman will be able to:

- Define vulvovaginities.

- List the causes and risk factors of vulvovaginitis.

- Discuss the symptoms of vulvovaginitis.

- Enumerate the complication of vulvovaginitis.

- Describe the management measure of vulvovaginitis.

- Explain the preventive measures of vulvovaginitis.

- Demonstrate the self-perineal care

\subsubsection{Implementation Phase}

The implementation of the current educational intervention guideline was implemented through (3) separate sessions. These sessions were repeated to each subgroup of (4-5) women. The duration of each session lasted from half an hour to one hour including periods of discussion according to their achievement, progress and feedback. At the beginning of the first session an orientation to the educational intervention and its aims took place. Feedback was given in the beginning of each session about the previous one. An educational hand out (Booklet) was developed by the researchers and given for each participants at the end of educational program.

\subsubsection{Evaluations Phase}

Two months after implementation of the educational intervention, the post test for women' knowledge and self-care practices were done by the same format of the pre-test to assess the impact of the implemented educational intervention.

\subsection{Statistical Design}

Data analysis was performed using Statistical Package for Social Sciences (SPSS version 22.0) Descriptive statistics were applied (e.g., mean, standard deviation, frequency and percentages). Test of significance (chi square, paired t test and One-way ANOVA test) was applied to test the study hypothesis. Correlation coefficient 
was calculated between knowledge, and practices scores. A statistically significant difference was considered at $\mathrm{p}$-value $\leq .05$, and a highly statistically significant difference was considered at $\mathrm{p}$-value $\leq .001$, while the p-value $>.05$ indicates non-significant results.

\section{Results}

Table 1 represents socio-demographic characteristics of the studied women. It was clear that $41.5 \%$ of the studied women were aged from $20 \leq 30$ years, with a mean of age $24.68 \pm 5.38$ years. Furthermore, $29.2 \%$ of them were secondary education. As regard their residence $53.8 \%$ of women resident in rural areas. In addition, $60 \%$ of them were housewives.

Table 2 displays that there were highly statistically significant differences $(\mathrm{P}<.001)$ before and after implementation of the educational intervention in relation to women' knowledge about definition, symptoms, causes, complication and preventive measures of vulvovaginitis.

Figure 1 illustrates that, only $9.2 \%$ of the women had adequate level before the educational intervention. However, the adequate level changed to be $86.2 \%$ after intervention.

Table 3 displays that, there were highly statistically significant differences $(\mathrm{P}<.001)$ before and after educational intervention in relation to all items regarding women general cleanness and menstrual hygienic practices.

Figure 2 demonstrates that, $87.7 \%$ of the women had an unsatisfactory level of self-care practices before the educational intervention. Meanwhile, after the educational intervention, $75.4 \%$ of them got a satisfactory level of self-care practices.

Table 4 shows the relationship between women' total knowledge score and their socio-demographic characteristics. There were highly statistically significant relations $(<0.001)$ between women' total knowledge score and their level of education, as well as statistically significant relations $(<0.05)$ between women' total knowledge scores and their working condition before intervention. On the other hands, there were no statistically significant differences $(>0.05)$ between women' total knowledge scores and their age and residence before and after the intervention.

Table 5 represents the relationship between women' total self-care practices and their socio- demographic characteristics. There was no statistically significant relations $(>0.05)$ between women' total self-care practices and their age, educational level, residence and occupation at both pre and post intervention phases.

Table 6 clarifies that, there was a positive, highly statistically significant correlation $(\mathrm{P} \leq .01)$ between women' total knowledge and practice scores before and after the educational intervention.

Table 7: distribution of studied woman outcomes pre-and post-guideline intervention. There was a highly significant difference regarding woman' outcomes at pre and post intervention phase.

Table 1. Distribution of studied women according to demographic characteristics $(\mathrm{n}=130)$

\begin{tabular}{lcc}
\hline Demographic characteristics & No & $\%$ \\
\hline Age in years & & \\
$-\quad 20 \leq 30$ & 54 & 41.5 \\
$-\quad 31 \leq 40$ & 46 & 35.4 \\
$-\quad 41-50$ & 30 & 23.1 \\
Mean \pm SD & & $24.68 \pm 5.38$ \\
Education level & 34 & \\
$-\quad$ Illiterate & 38 & 26.2 \\
$-\quad$ Read and write & 26 & 29.2 \\
$-\quad$ Secondary education & 32 & 20.0 \\
$-\quad$ High education & 70 & 24.6 \\
Residence & 60 & 53.8 \\
$-\quad$ Rural & & 46.2 \\
- Urban & 52 & \\
Occupation & 78 & 40.0 \\
$-\quad$ Worked & & 60.0 \\
$-\quad$ House wife & &
\end{tabular}


Table 2. Distribution of the studied subjects according to their general knowledge regarding vulvovaginitis before and after educational intervention $(\mathrm{n}=130)$

\begin{tabular}{|c|c|c|c|c|c|c|c|c|c|c|}
\hline \multirow[t]{3}{*}{ Knowledge } & \multicolumn{4}{|c|}{ Pre-intervention } & \multicolumn{4}{|c|}{ Post-intervention } & \multirow{3}{*}{$\begin{array}{c}\text { Chi } \\
\text { square } \\
\text { test }\end{array}$} & \multirow[t]{3}{*}{ P value } \\
\hline & \multicolumn{2}{|c|}{ Incorrect } & \multicolumn{2}{|c|}{ Correct } & \multicolumn{2}{|c|}{ Incorrect } & \multicolumn{2}{|c|}{ Correct } & & \\
\hline & No & $\%$ & No & $\%$ & No & $\%$ & No & $\%$ & & \\
\hline Definition of infection & 78 & $60.0 \%$ & 52 & $40.0 \%$ & 30 & $23.1 \%$ & 100 & 76.9 & 36.49 & $<0.001 * *$ \\
\hline Definition of vulvovaginitis & 90 & $69.2 \%$ & 40 & $30.8 \%$ & 34 & $26.2 \%$ & 96 & 73.8 & 48.34 & $<0.001 * *$ \\
\hline \multicolumn{11}{|l|}{ Causative agent of vulvovaginitis } \\
\hline Candidiasis & 92 & $70.8 \%$ & 38 & $29.2 \%$ & 38 & $29.2 \%$ & 92 & 70.8 & 44.86 & $<0.001^{* *}$ \\
\hline Bacterial vaginosis & 86 & $66.2 \%$ & 44 & $33.8 \%$ & 40 & $30.8 \%$ & 90 & 69.2 & 32.58 & $<0.001^{* *}$ \\
\hline Aerobic vaginitis & 92 & $70.8 \%$ & 38 & $29.2 \%$ & 22 & $16.9 \%$ & 108 & 83.1 & 76.54 & $<0.001^{* *}$ \\
\hline \multicolumn{11}{|l|}{ Symptoms of vulvovaginitis } \\
\hline irritation and/or itching of the genital area & 92 & $70.8 \%$ & 38 & $29.2 \%$ & 18 & $13.8 \%$ & 112 & 86.2 & 86.28 & $<0.001^{* *}$ \\
\hline $\begin{array}{l}\text { inflammation of the labia majora, labia minora, or perineal } \\
\text { area }\end{array}$ & 84 & $64.6 \%$ & 46 & $35.4 \%$ & 22 & $16.9 \%$ & 108 & 83.1 & 61.22 & $<0.001 * *$ \\
\hline vaginal discharge & 94 & $72.3 \%$ & 36 & $27.7 \%$ & 44 & $33.8 \%$ & 86 & 66.2 & 38.60 & $<0.001 * *$ \\
\hline foul vaginal odor & 88 & $67.7 \%$ & 42 & $32.3 \%$ & 28 & $21.5 \%$ & 102 & 78.5 & 56.03 & $<0.001^{* *}$ \\
\hline pain/irritation with sexual intercourse & 102 & $78.5 \%$ & 28 & $21.5 \%$ & 34 & $26.2 \%$ & 96 & 73.8 & 71.29 & $<0.001 * *$ \\
\hline \multicolumn{11}{|l|}{ Causes of vulvovaginitis } \\
\hline Infection & 94 & $72.3 \%$ & 36 & $27.7 \%$ & 36 & $27.7 \%$ & 94 & 72.3 & 51.75 & $<0.001 * *$ \\
\hline Hormonal & 84 & $64.6 \%$ & 46 & $35.4 \%$ & 34 & $26.2 \%$ & 96 & 73.8 & 38.79 & $<0.001 * *$ \\
\hline Irritation /allergy & 88 & $67.7 \%$ & 42 & $32.3 \%$ & 36 & $27.7 \%$ & 94 & 72.3 & 41.68 & $<0.001^{* *}$ \\
\hline \multicolumn{11}{|l|}{ Complication of vulvovaginitis } \\
\hline Occurrence of lump & 96 & $73.8 \%$ & 34 & $26.2 \%$ & 36 & 27.7 & 94 & 72.3 & 55.39 & $<0.001^{* *}$ \\
\hline Dystrophy on the vulva & 90 & $69.2 \%$ & 40 & $30.8 \%$ & 26 & $20.0 \%$ & 104 & 80.0 & 63.75 & $<0.001^{* *}$ \\
\hline Infertility & 96 & $73.8 \%$ & 34 & $26.2 \%$ & 36 & $27.7 \%$ & 94 & 72.3 & 55.39 & $<0.001^{* *}$ \\
\hline Cancer in external genital organ & 90 & $69.2 \%$ & 40 & $30.8 \%$ & 36 & $27.7 \%$ & 94 & 72.3 & 44.90 & $<0.001^{* *}$ \\
\hline Internal genital organ such as inflammation & 100 & $76.9 \%$ & 30 & $23.1 \%$ & 28 & $21.5 \%$ & 102 & 78.5 & 79.77 & $<0.001 * *$ \\
\hline \multicolumn{11}{|l|}{ preventive measures of vulvovaginitis } \\
\hline Hygienic care & 96 & $73.8 \%$ & 34 & $26.2 \%$ & 28 & $21.5 \%$ & 102 & $78.5 \%$ & 71.29 & $<0.001 * *$ \\
\hline avoidance of factors that lead to genital infection & 84 & $64.6 \%$ & 46 & $35.4 \%$ & 20 & $15.4 \%$ & 110 & $84.6 \%$ & 65.64 & $<0.001 * *$ \\
\hline avoidance of using of public bathes & 104 & $80.0 \%$ & 26 & $20.0 \%$ & 20 & $15.4 \%$ & 110 & $84.6 \%$ & 108.78 & $<0.001 * *$ \\
\hline cleaning and dryness the genital organs & 98 & $75.4 \%$ & 32 & $24.6 \%$ & 14 & $10.8 \%$ & 116 & $89.2 \%$ & 110.67 & $<0.001 * *$ \\
\hline wearing cotton clothes & 96 & $73.8 \%$ & 34 & $26.2 \%$ & 18 & $13.8 \%$ & 112 & 86.2 & 95.04 & $<0.001^{* *}$ \\
\hline avoidance of using of removal hair cream & 78 & $60.0 \%$ & 52 & $40.0 \%$ & 30 & $23.1 \%$ & 100 & 76.9 & 36.49 & $<0.001^{* *}$ \\
\hline
\end{tabular}

**A highly statistical significant difference $(\mathrm{P} \leq .001)$

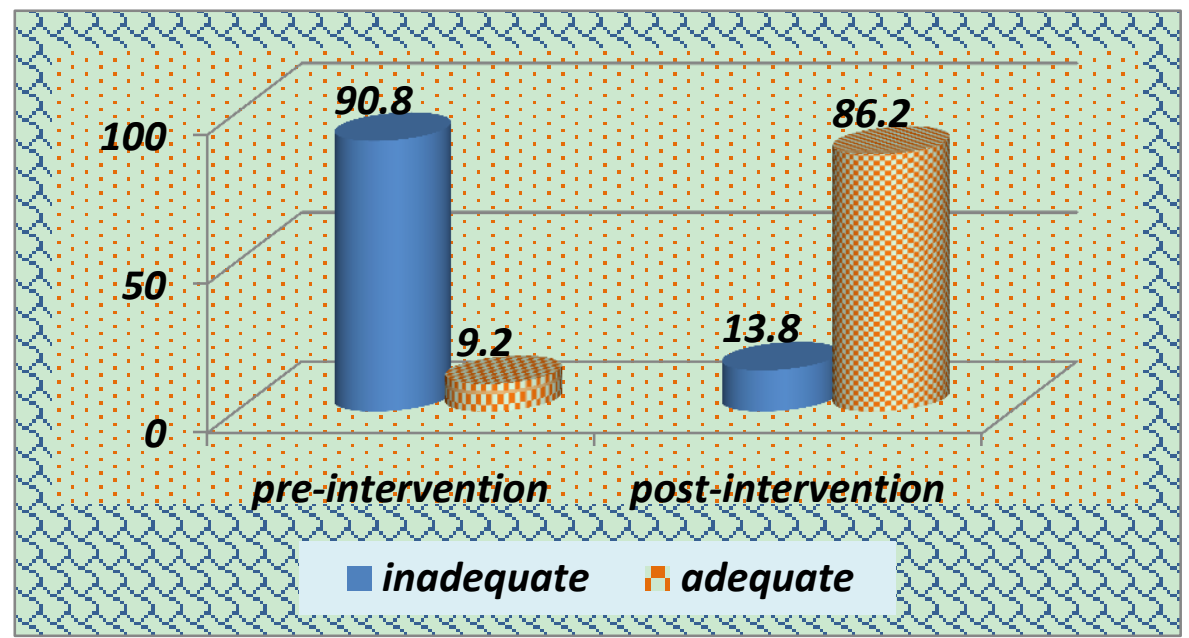

Figure 1. Distribution of the study subjects according to their total knowledge scores before and after educational intervention $(\mathrm{n}=130)$ 
Table 3. Distribution of the studied subjects according to their self-care practices regarding vulvovaginitis before and after educational intervention $(\mathrm{n}=130)$

\begin{tabular}{|c|c|c|c|c|c|c|c|c|c|c|c|}
\hline & & \multicolumn{4}{|c|}{ Pre-intervention } & \multicolumn{4}{|c|}{ Post-intervention } & \multirow{3}{*}{$\begin{array}{c}\text { Chi } \\
\text { square } \\
\text { test }\end{array}$} & \multirow[t]{3}{*}{ P value } \\
\hline & & \multicolumn{2}{|c|}{ Done } & \multicolumn{2}{|c|}{ Not done } & \multicolumn{2}{|c|}{ Done } & \multicolumn{2}{|c|}{ Not done } & & \\
\hline & & No & $\%$ & No & $\%$ & No & $\%$ & No & $\%$ & & \\
\hline \multicolumn{12}{|c|}{ General cleanness practices } \\
\hline - & Clean genital area after each toilet & 86 & $66.2 \%$ & 44 & $33.8 \%$ & 30 & $23.1 \%$ & 100 & $76.9 \%$ & 48.81 & $<0.001^{* * *}$ \\
\hline - & Dry after cleanliness & 106 & $81.5 \%$ & 24 & $18.5 \%$ & 16 & $12.3 \%$ & 114 & $87.7 \%$ & 125.08 & $<0.001^{* * *}$ \\
\hline- & Wear cotton underwear & 94 & $72.3 \%$ & 36 & $27.7 \%$ & 22 & $16.9 \%$ & 108 & $83.1 \%$ & 80.69 & $<0.001 * *$ \\
\hline- & Wear loose under wear & 78 & $60.0 \%$ & 52 & $40.0 \%$ & 28 & $21.5 \%$ & 102 & $78.5 \%$ & 39.81 & $<0.001 * *$ \\
\hline - & Continuous change of underwear don't be media for infection & 94 & $72.3 \%$ & 36 & $27.7 \%$ & 28 & $21.5 \%$ & 102 & $78.5 \%$ & 67.27 & $<0.001 * *$ \\
\hline- & $\begin{array}{l}\text { Use cleaning substance as (cholorine, potash)cause genital } \\
\text { irritation }\end{array}$ & 94 & $72.3 \%$ & 36 & $27.7 \%$ & 32 & $24.6 \%$ & 98 & $75.4 \%$ & 59.19 & $<0.001 * *$ \\
\hline - & Use hair removal cream & 74 & $56.9 \%$ & 56 & $43.1 \%$ & 34 & $26.2 \%$ & 96 & $73.8 \%$ & 25.34 & $<0.001 * *$ \\
\hline - & Washing under wear with hot water and soup & 80 & $61.5 \%$ & 50 & $38.5 \%$ & 36 & $27.7 \%$ & 94 & $72.3 \%$ & 30.13 & $<0.001 * *$ \\
\hline - & Expose clothes to sun rays & 96 & $73.8 \%$ & 34 & $26.2 \%$ & 26 & $20.0 \%$ & 104 & $80.0 \%$ & 75.67 & $<0.001 * *$ \\
\hline- & Laundry the clothes before wear & 91 & $70.0 \%$ & 39 & $30.0 \%$ & 25 & $19.2 \%$ & 105 & $80.8 \%$ & 67.80 & $<0.001^{* *}$ \\
\hline- & Use napikins & 79 & $60.8 \%$ & 51 & $39.2 \%$ & 18 & $13.8 \%$ & 112 & $86.2 \%$ & 61.18 & $<0.001 * *$ \\
\hline \multicolumn{12}{|c|}{ Practice regarding menstrual hygiene } \\
\hline- & Take bath during menstruation & 95 & $73.1 \%$ & 35 & $26.9 \%$ & 16 & $12.3 \%$ & 114 & $87.7 \%$ & 98.11 & $<0.001 * *$ \\
\hline- & Clean genital area during bathing & 87 & $66.9 \%$ & 43 & $33.1 \%$ & 11 & $8.5 \%$ & 119 & $91.5 \%$ & 94.59 & $<0.001 * *$ \\
\hline- & Bathing in standing not setting & 82 & $63.1 \%$ & 48 & $36.9 \%$ & 14 & $10.8 \%$ & 116 & $89.2 \%$ & 76.36 & $<0.001 * *$ \\
\hline- & Disinfect or clean genital toilet before and after use & 70 & $53.8 \%$ & 60 & $46.2 \%$ & 25 & $19.2 \%$ & 105 & $80.8 \%$ & 33.58 & $<0.001 * *$ \\
\hline- & Use sanitary pad & 79 & $60.8 \%$ & 51 & $39.2 \%$ & 25 & $19.2 \%$ & 105 & $80.8 \%$ & 46.73 & $<0.001 * *$ \\
\hline - & Sanitary pad should be made from cotton & 98 & $75.4 \%$ & 32 & $24.6 \%$ & 14 & $10.8 \%$ & 116 & $89.2 \%$ & 110.67 & $<0.001^{* * *}$ \\
\hline- & Change pad every each bath & 89 & $68.5 \%$ & 41 & $31.5 \%$ & 17 & $13.1 \%$ & 113 & $86.9 \%$ & 82.56 & $<0.001 * *$ \\
\hline- & Use only personal hygiene instruments & 70 & $53.8 \%$ & 60 & $46.2 \%$ & 23 & $17.7 \%$ & 107 & $82.3 \%$ & 36.98 & $<0.001^{* *}$ \\
\hline - & Expose personal hygiene instruments to sun rays & 82 & $63.1 \%$ & 48 & $36.9 \%$ & 23 & $17.7 \%$ & 107 & $82.3 \%$ & 55.61 & $<0.001^{* *}$ \\
\hline
\end{tabular}

**A highly statistical significant difference $(\mathrm{P} \leq .001)$

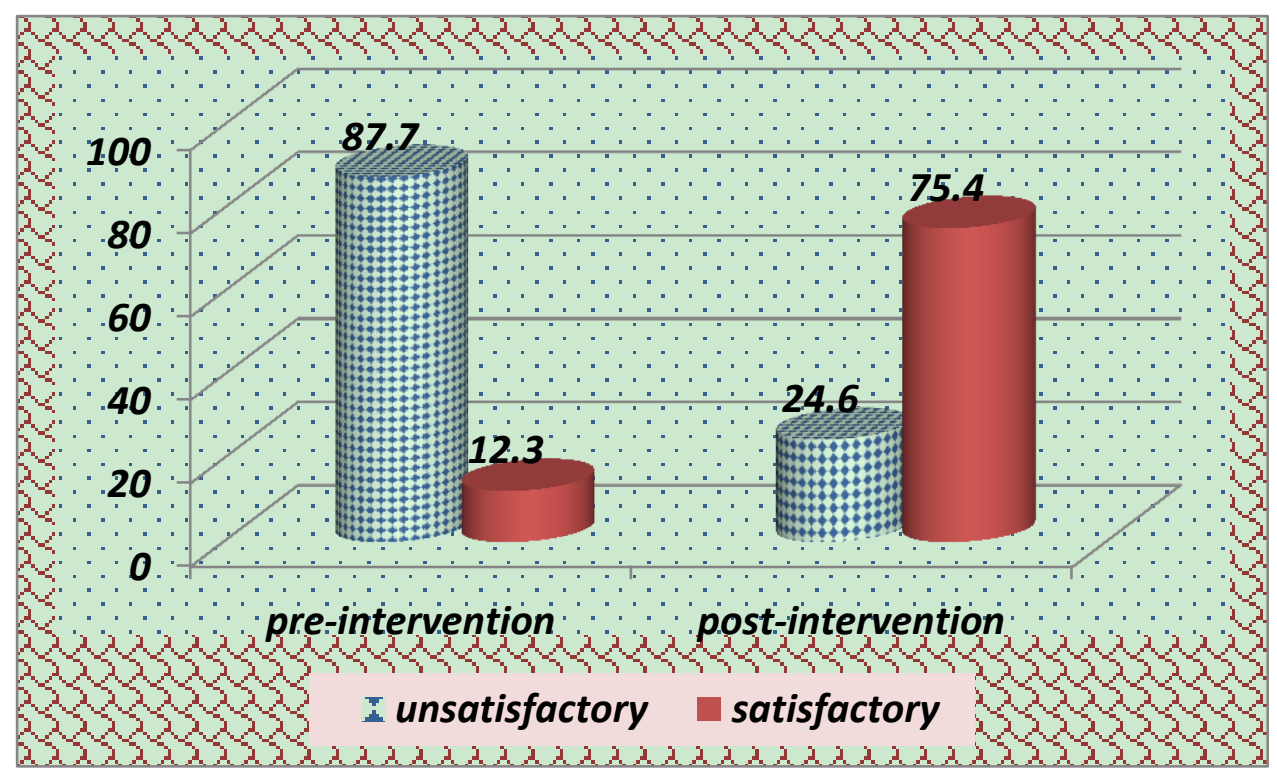

Figure 2. Distribution of the study subjects according to their total self-care practices scores before and after educational intervention $(n=130)$ 
Table 4. Relation between women's total knowledge score and their socio demographic characteristics before and after educational intervention $(\mathrm{n}=130)$

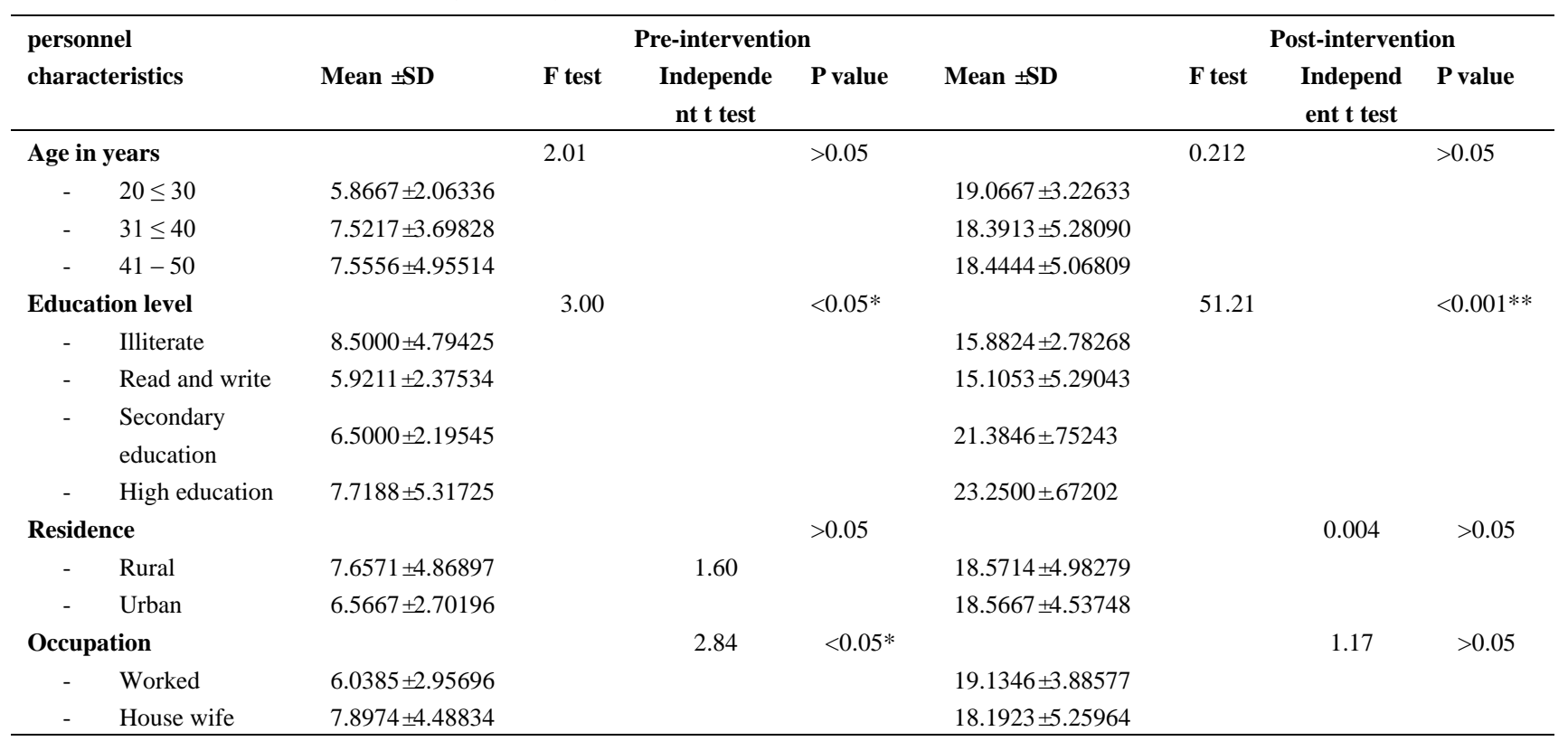

F: One-way ANOVA test, **A highly statistical significant difference $(\mathrm{P} \leq .001)$

Table 5. Relation between women's total practices score and their personnel characteristics before and after educational intervention $(n=130)$

\begin{tabular}{|c|c|c|c|c|c|c|c|c|c|}
\hline \multicolumn{2}{|c|}{ personnel characteristics } & \multicolumn{4}{|c|}{ Pre-intervention } & \multicolumn{4}{|c|}{ Post-intervention } \\
\hline & & Mean \pm SD & $F$ test & $\begin{array}{l}\text { Independent } \\
t \text { test }\end{array}$ & $P$ value & Mean \pm SD & F test & $\begin{array}{l}\text { Independent } \\
\text { t test }\end{array}$ & $P$ value \\
\hline Age i & & & 0.563 & & $>0.05$ & & 1.13 & & $>0.05$ \\
\hline- & $20 \leq 30$ & $6.3333 \pm 3.87150$ & & & & $17.3333 \pm 2.13886$ & & & \\
\hline- & $31 \leq 40$ & $7.2826 \pm 3.91387$ & & & & $16.3043 \pm 4.83905$ & & & \\
\hline- & $41-50$ & $6.5000 \pm 4.98204$ & & & & $16.0556 \pm 3.51502$ & & & \\
\hline \multicolumn{2}{|c|}{ Education level } & & 10.26 & & $<0.001^{*}$ & & 38.15 & & $<0.001 *$ \\
\hline- & Illiterate & $9.7941 \pm 4.30489$ & & & $*$ & $14.3529 \pm 2.11606$ & & & $*$ \\
\hline- & Read and write & $4.8158 \pm 3.03008$ & & & & $13.9474 \pm 4.73028$ & & & \\
\hline- & Secondary education & $5.7692 \pm 3.08944$ & & & & $18.4231 \pm .50383$ & & & \\
\hline- & High education & $6.5625 \pm 5.04136$ & & & & $20.0000 \pm .00000$ & & & \\
\hline \multicolumn{2}{|c|}{ Residence } & & & 0.149 & $>0.05$ & & & 0.078 & $>0.05$ \\
\hline- & Rural & $6.6857 \pm 4.60165$ & & & & $16.4143 \pm 3.94709$ & & & \\
\hline- & Urban & $6.8000 \pm 4.11611$ & & & & $16.4667 \pm 3.67984$ & & & \\
\hline \multicolumn{2}{|c|}{ Occupation } & & & & $>0.05$ & & & 1.30 & $>0.05$ \\
\hline- & Worked & $6.5769 \pm 4.96526$ & & 0.612 & & $15.1923 \pm 5.49195$ & & & \\
\hline- & House wife & $6.0769 \pm 4.39728$ & & & & $16.2821 \pm 5.51528$ & & & \\
\hline
\end{tabular}

F: One-way ANOVA test

Table 6. Correlation coefficient between study subjects' total knowledge and practices scores before and after educational intervention $(n=64)$

\begin{tabular}{|c|c|c|}
\hline Vorioblo & Practice pre-intervention & Practice post-intervention \\
\hline variaties & R $\quad$ P value & $\begin{array}{ll}\mathbf{r} & \text { P value }\end{array}$ \\
\hline Knowledge pre-intervention & $.439^{* *}$ & \\
\hline Knowledge post-intervention & - & $.496^{* *}$ \\
\hline
\end{tabular}

$* *$ Correlation is highly statistically significant at $\mathrm{P} \leq .01$ 
Table 7. Distribution of studied women outcomes pre and post guidelines intervention $(n=130)$

\begin{tabular}{|c|c|c|c|c|c|c|c|c|c|c|}
\hline \multirow[b]{3}{*}{ Proper sexual relation } & \multicolumn{4}{|c|}{ Pre-intervention } & \multicolumn{4}{|c|}{ Post-intervention } & \multirow{3}{*}{$\begin{array}{l}\begin{array}{l}\text { Chi square } \\
\text { test }\end{array} \\
104.00\end{array}$} & \multirow{3}{*}{$\begin{array}{l}\text { P value } \\
<0.001 * *\end{array}$} \\
\hline & \multicolumn{2}{|c|}{ Yes } & \multicolumn{2}{|c|}{ No } & \multicolumn{2}{|c|}{ Yes } & \multicolumn{2}{|c|}{ No } & & \\
\hline & 90 & $69.2 \%$ & 40 & $30.8 \%$ & 10 & $7.7 \%$ & 120 & $92.3 \%$ & & \\
\hline $\begin{array}{l}\text { Absence of pain during } \\
\text { sexual relation }\end{array}$ & 100 & $76.9 \%$ & 30 & $23.1 \%$ & 16 & $12.3 \%$ & 114 & $87.7 \%$ & 109.82 & $<0.001 * *$ \\
\hline High self esteem & & & & & & & & & & $<0.001 * *$ \\
\hline No embarrassment of odor & 100 & $76.9 \%$ & 30 & $23.1 \%$ & 18 & $13.8 \%$ & 112 & $86.2 \%$ & 104.33 & $<0.001 * *$ \\
\hline $\begin{array}{l}\text { Confidence during Social } \\
\text { interaction }\end{array}$ & 104 & $80.0 \%$ & 26 & $20.0 \%$ & 12 & $9.2 \%$ & 118 & $90.8 \%$ & 141.74 & $<0.001 * *$ \\
\hline Proper sleeping pattern & 102 & $78.5 \%$ & 28 & $21.5 \%$ & 14 & $10.8 \%$ & 116 & $89.2 \%$ & 120.53 & $<0.001 * *$ \\
\hline & 106 & $81.5 \%$ & 24 & $18.5 \%$ & 14 & $10.8 \%$ & 116 & $89.2 \%$ & 130.99 & $<0.001 * *$ \\
\hline
\end{tabular}

\section{Discussion}

The present study was conducted to evaluate the effect of educational intervention guideline on knowledge and self-care practices for women with vulvovaginities. Concerning women' total knowledge about vulvovaginities, the present study findings revealed that, the minority of the women had in adequate knowledge before educational intervention. However, after educational intervention the adequate knowledge changed to be for the majority. The decrease of the percentage of the nurses' adequate knowledge level before educational intervention may be due to that most of the studied women were illiterate and read and write.

The present study findings showed highly significant improvement in the women' knowledge regarding all items related to vulvovaginities after the educational intervention as compared to before the intervention. The results of the present study agree with other researches. First Parsapur (2015) who had conducted his study in Tehran-Iran and confirmed the positive effects of health education on improvement of knowledge, attitude practice, and duration of fungal vaginitis treatment. Also concluded that health education is an efficient method for improving the related variables. Entisar et al. (2017) In addition who stated that the mean score of knowledge of the studied sample as regards the anatomy of the female reproductive system, natural defense mechanism in the female genital system, and characteristics of normal vaginal discharge were significantly improved after implementation of educational program. Moreover Chauhan et al. (2014) who studied the effectiveness of planned teaching program about knowledge related to reproductive tract infections (RTIs )among rural women. Reported that there were a significant difference between the mean pre and post-test knowledge related to anatomy, physiology of reproductive tract, and types of genital tract infections. Thus, it is interpreted that planned teaching program was effective in increasing the knowledge of women as regards vulvovaginities.

Entisar et al. (2017) supported the current study results. The former had studied "the effectiveness of planned educational program on vaginitis and its preventive measures on adolescent female nursing student's knowledge" and found that the mean post-test knowledge score was higher as compared with the mean pretest knowledge score. The scores predicted that there was a significant difference between the mean pre and post-test scores at $(\mathrm{P}$ $<0.05 *)$ level.

As regards the correct knowledge of women about vulvovaginitis the result of present study revealed that the overall percentage of adequate knowledge related to bacterial vaginosis improved after the intervention program with a highly significant difference. This goes in line with Majlesi et al. (2015) who clarified that the effect of health education on knowledge, attitude and performance of women of reproductive age with fungal vaginitis demonstrated that the education has an increasing effect on knowledge. Since the purpose of this study it was hard for them to gather and present, training was conducted individually in the clinic and this caused increasing in women level of knowledge. On other hand these findings disagreed with Renju (2010) who mentioned that the knowledge scores between the intervention and control groups had no significant difference before and after training and after intervention. Also Bahram et al. (2009) who addressed that a significant correlation between BV and educational status, which in comparison to other similar studies, it was evident that the lack of education has been found to be significantly associated.

Regarding to total self-practice scores of the studied women, the present study revealed that there were highly statistically significant differences $(\mathrm{P}<.001)$ between pre and post intervention in relation to women' practices regarding vulvovaginities. These results are in accordance with Yarmohammadi et al. (2015) in the study to evaluate "the effect of education on knowledge, attitude and practice of patients with vaginitis' ' showed that the performance was a highly statistically significant increase compared to its previous status in intervention group, 
while the study evaluated the impact of health education in the first and second level of organization: prevention of infection by Trichomonas, Candida and Health, vaginal herpes and showed significant increase after the intervention compared to its previous status in relation to trichomona, gardenella and gonorrhoea vaginitis and health care by women. In accordance with Eman elsayed (2016), the study conducted on impact of intervention program on non-pregnant women's knowledge and genital hygiene practices regarding bacterial vaginosis suggested that the overall mean increase in adequate practice improved from 3.90 \pm 2.41 to $5.40 \pm 1.19$ after the intervention program, with a highly significant difference. On the same line Soudabeh et al. (2015) found that after education, the performance score showed a significant increase compared to its previous status in intervention group. Researchers believe that having information and knowledge alone is not sufficient to perform self-care practice, but the thought and attitude about disease is an important factor to do or not to do a preventive measure and thoughts lead to behavior and action

According to self-care practices the present study showed that there were a highly statistically significant differences $(\mathrm{P}<.001)$ in relation to all item of self-practice (general cleanness practice and menstrual hygienic practice before and after educational intervention. In contrast with study by Lic et al. (2010) "An Evaluation of the Relationship between Genital Hygiene Practices. Genital Infection Gynecol. Obstet" reported that one third of sample good practice such as changing underwear, wearing cotton underwear and keeping the area dry completely to overcome vaginal infection.

Regarding the relationship between women' total knowledge, practices scores and their socio- demographic characteristics. The present study revealed that, there were highly statistically significant relations between women' total knowledge score and their level of education, as well as women' total knowledge scores and their working condition before intervention. This result is compatible with Ebrahimi et al. (2015) " Assessment of educational needs among women of reproductive age with common genital tract infections (Vaginitis): The First Step for Developing a Self-care Educational Package " reported that there were positive effect of education on improvement of knowledge and practice in some types of vaginitis.

It was found from the results of the current study that, there was a positive highly statistically significant correlation between studied women total knowledge and self-care practices of vulvovaginitis pre and post intervention. This result is in agreement with Suki and hatamian (2014) the study conducted on woman's practice and knowledge concerning the genital tract health in Shahid Beheshti hospital, Iran, suggested that women be educated in suitable locations including health centers through educational pamphlets, in order to change their performance.

These findings are in agreed with Jalali et al. (2014) who clarified that knowledge and health belief about UTI are considered to be motivating factors for behavior change. These findings are in congruence with Yossif et al., (2014) who clarified that, there was a positive highly statistically significant correlation between total knowledge and total health beliefs scores as well as between total knowledge and total intention to practice health behavior in both intervention and control groups before and two months after self-learning package. Also Rahimi et al., (2016) showed a significant correlation between knowledge and all HBM construct with health behavior. This may be attributed to the fact that changing the belief is the milestone for behavior change. All these studies based on HBM which play on changing the belief.

However, these findings were disagreed with Renju (2010) the findings of studied the effect of planned educational program about vaginitis on students' knowledge and found that there was no association between pretest knowledge score and selected demographic variables.

\section{Conclusion}

Based on the results of the present study, it can be concluded that, there was a statistically significant improvement in women' knowledge and self-care practices after the educational intervention. The implementation of an educational guideline significantly improved women' knowledge and self-care practices towards management and prevention of vulvovaginities. Moreover, the above mentioned results proved the study hypothesis.

\section{Recommendations}

Based on results of the present study, the following recommendations can be suggested:

- Provide different educational programs regarding knowledge and self-care practice for women with vulvovaginities at different female health care settings.

- Nurses should provide all reproductive age women with instructional booklets about vulvovaginities to improve their knowledge, and self-care practices. 
- Replication of this study on a large sample and in different settings is recommended for generalization of results.

\section{Acknowledgements}

The authors would like to express their appreciation to all participants who willingly participated in the study.

\section{References}

Ali, R., \& Hussien, A.S. (2017). Assessment of Health Behaviors Knowledge Regarding Vaginal Discharge among Women Attending Maternity Hospitals in Baghdad City. IOSR Journal of Nursing and Health Science, 6(4), 31-36. https://doi.org/10.9790/1959-0604023136

Bahram, A., Baghchesaraie, H., \& Torabi, Z. (2009). Prevalence of Bacterial Vaginosis and Impact of Genital, HygienePractices in Non-Pregnant Women in Zanjan, Iran. OMJ., 24, 288-293.

Barry, L., Hainer, M.D., Maria, V., \& Gibson, MD. (2011). Medical University of South Carolina, Charleston, South Carolina (C 2011 American Academy of Family Physicians. Retrieved from http://www.aafp.org/afp

Bilardi, J., Walker, S., McNair, R., Mooney-Somers, J., Temple-Smith, M., Bellhouse, C., et al. (2016). Women's Management of Recurrent Bacterial Vaginosis and Experiences of Clinical Care: A Qualitative Study. PLoS ONE, 11(3), e0151794. https://doi.org/10.1371/journal.pone.0151794

Chauhan, A., Chawla, D., Saini, G., Rawat, H., Pundir, K., Kumar, L., \& Benjamin, P. (2014). Effectiveness of a 'planned teaching program' (PTP) on knowledge related to reproductive tract infections among rural women. IOSRJ Nurs Health Sci., 3, 17.

Ebrahimi, T., Ghofranipour, F., HajizadehE, \& Abedini, M. (2015, October). Assessment of Educational Needs Among Women of Reproductive Age With Common Genital Tract Infections (Vaginitis): The First Step for Developing a Self-care Educational Package. International Journal of Women's Health and Reproduction Sciences, 3(4), 201-207. https://doi.org/10.15296/ijwhr.2015.42

Eman Elsayed Mohammed Elsabagh. (2016). Impact of Intervention Program on Non Pregnant Women's Knowledge and Genital Hygiene Practices Regarding Bacterial Vaginosis. International Journal of Current Research, 8(11), 41864-41874.

Entisar, M., Youness, A., \& Ayat, M.O. (2017). Effectiveness of planned educational program on vaginitis and its preventive measures on adolescent female nursing student's knowledge. Egyptian Nursing Journal, 14(1).

Gor, H.B. (2015). Vaginitis, background, pathophysiology, etiology. Retrieved from http://emedicine.medscape.com/article/257

Gupta, G., Nandwani, S., \& Agarwal, A. (2013). Prevalence of candidiasis, trichomoniasis and bacterial vaginosis among women of reproductive age group. Indian Journal of Public Health Research and Development, 4(2), 94-98.

Jalali, M., Shamsi, M., Roozbehani, N., \& Kabir, K. (2014). Investigation of health education based on theory of planned behavior on behavioral promotion of urinary infection prevention in pregnant women. World Journal of Medical Sciences, 11(4), 452-460.

Li, C., Han, H.R., Lee, J.E., Lee, M., Lee, Y., \& Kim, M.T. (2010). Knowledge, behaviors and prevalence of reproductive tract infections: a descriptive study on rural women in hunchun, china. Asian Nurs Res (Korean Soc Nurs Sci), 4(3), 122-129. https://doi.org/10.1016/S1976-1317(10)60012-6

Majlesi, F.R., Parsa Poor, M., Mahmoudi, H., \& Eftekhar, A. (2015). Effect of health education on knowledge, attitude, practice and treatment duration of fungal vaginitis in women at fertility age. Tehran: School of Public Health Tehran, University of Medical Sciences.

Mulu, W., Yimer, M., Zenebe, Y., \& Abera, B. (2015). Common causes of vaginal infections and antibiotic susceptibility of aerobic bacterial isolates in women of reproductive age attending at Felegehiwot Referral Hospital, Ethiopia: a cross sectional study. BMC Women's Health. https://doi.org/10.1186/s12905-015-0197-y

Parsapur, R. (2015). Effectiveness of Health education on Knowledge, Attitude and Practice (KAP) and Treatment period of women with fungal vaginitis (candidiasis). Tehran: Tehran University of Medical Sciences, Public Health Faculty.

Rahimi, S.F., Zareban, I., Shahrakipoor, M., Zhianian, A., Keykhaee, Z., Hosseini, E., \& karami bojd, F. (2016). Predictors of preventive behaviors of urinary tract infections based on health belief model among pregnant 
women in Zahedan. Caspian Journal of Health Research, 1(2), 9-17. https://doi.org/10.18869/acadpub.cjhr.2.1.9

Renju, S. (2010). Effectiveness of planned teaching program (PTP) on vaginitis and its prevention among adolescents of selected pupil colleges in Mangalore. Bangalore, Karnataka, India: Rajiv Gandhi University of Health Sciences.

Soudabeh, Y.A., Seyyedeh, S.A., Mousavi, M.O., \& Sheikhehpo, A.R. (2015). The Effect of Education on Knowledge,Attitudeand Practice of Patients with Vaginitis. Advances Biological Research, 9(3), 196-200.

Suki, Z., \& Hatamian, S. (2014). Assessment of Knowledge and Practice about Genital Health among reproductive age women referred to Shahid Beheshti Hospital in Kashan (Iran). Proceeding of the Seminar: Sexual Health in fertility and infertility. Retrieved from http:// www.avicenna.ac.ir/PDF/Pe/SM/10.pdf

World Health Organization. (2013). Sexually Transmitted Infections, The importance of a renewed commitment to STI prevention and control in achieving global sexual and reproductive health. Retrieved from http://apps.who.int/ iris/bitstream/10665/82207/1/WHO_RHR_13.02_eng.pdf

Yarmohammadi, S., Taheri, G., Mousavi, S.S., Sheikhehpour, M., Paykoub, M.H., \& Hashemian, A.H. (2015). The Effect of Education on Knowledge, Attitude and Practice of Patients with Vaginitis. Adv Biol Res., 9(3), 196-200.

Yossif, H.A., \& EL Sayed, H.A. (2014). Effect of self-learning package based on health belief model on cervical cancer prevention among female University students. IOSR Journal of Nursing and Health Science, 3(6), 77-88.

\section{Copyrights}

Copyright for this article is retained by the author(s), with first publication rights granted to the journal.

This is an open-access article distributed under the terms and conditions of the Creative Commons Attribution license (http://creativecommons.org/licenses/by/4.0/). 